\title{
LITERATURA ELETRÔNICA E ENSINO: a poesia de Carlos Vogt ${ }^{1}$
}

\author{
Edgar Roberto Kirchof - \\ ekirchofepq.cnpq.br
}

Simone Assumpção

UNISINOS

simone.assumpcao@uol.com.br

\begin{abstract}
Resumo
A tecnologia digital propicia o surgimento de novos gêneros discursivos e, consequentemente, cria novos percursos de leitura e de aprendizagem. O presente artigo, após uma breve explanação sobre algumas particularidades da linguagem em ambiente eletrônico, apresenta alguns dos principais argumentos recentes que procuram situar os novos gêneros eletrônicos a partir de supostos benefícios ou malefícios para a cultura e o ensino. Em seguida, apresenta-se uma breve análise da poesia digital enquanto um gênero eletrônico profícuo quanto a possibilidades de aproximação entre a cibercultura e o Ensino, a partir de dois poemas de Carlos Vogt.
\end{abstract}

\section{Palavras-chave}

Poesia digital - Literatura eletrônica - Ensino

\section{Abstract}

Digital technology serves as a support for the irruption of new textual genres and, therefore, creates new reading and learning processes. The present article begins by presenting some

1 O presente artigo integra o Projeto de Pesquisa Literatura digital e educação: novas identidades de leitor a partir da cibercultura, com apoio do CNPq, assim como da ULBRA-RS (bolsa de Iniciação Científica), em desenvolvimento no PPGEdu-ULBRA, RS. 
of the main recent arguments that are frequently used to support supposed benefits or harms of electronic texts in relation to culture and learning. Thereafter two digital poems by Carlos Vogt are analyzed, since digital poetry seems a very appropriate eletronic genre as it performs an approximation between cyber culture and Education.

\section{Key-words}

Digital poetry - Electronic literature - Education

\section{Introdução}

Segundo estudos recentes relativos à linguagem em ambiente virtual (Coscarelli; Ribeiro, 2005; Meyer; Simanowski; Zeller, 2006; Araújo, 2007), as tecnologias vinculadas ao computador propiciam o surgimento de novos gêneros textuais ou discursivos e, consequentemente, são capazes de criar percursos de leitura e de aprendizagem até então inexistentes ou pouco explorados. Nas palavras de Araújo e Costa (2007, p. 21), a Internet constitui um "espaço sócio-discursivo que amplia as possibilidades de interação e incita o surgimento de vários gêneros discursivos".

Nesse contexto, é necessário destacar que o surgimento bem como o consequente desenvolvimento dos assim chamados gêneros digitais (Marchuschi; Xavier, 2004) apresentam uma série de novos desafios para o campo do Ensino, na medida em que estes parecem redimensionar o próprio veículo a partir do qual se realiza todo e qualquer ato educacional: a linguagem humana. Por essa razão, caracterizam-se como objetos culturais privilegiados para um trabalho, na área da Educação, que visa a compreender a cultura digital. Em meio a esse contexto, o presente trabalho discute algumas questões 
ligadas ao processo da leitura literária em ambiente digital, focalizando a poesia digital.

o artigo inicia com uma breve explanação sobre algumas particularidades de que a linguagem se reveste, uma vez situada em ambiente virtual, discutindo, brevemente, a maneira polarizada como tais inovações têm sido interpretadas no âmbito do ensino. Em seguida, após apresentar, também em breves traços, como a literatura contemporânea tem se modificado devido à sua inserção em ambientes virtuais, o artigo ensaia uma análise de dois poemas digitais de Carlos Vogt, cujo desenho e concepção visual são de autoria de João Baptista da Costa Aguiar e cuja realização é de responsabilidade de Evelina Azeredo Rios.

Linguagem em ambiente digital

A partir das décadas de 80 e 90 do século XX, um novo meio de comunicação torna-se rapidamente popular e cada vez mais acessível a uma ampla camada da população: o computador. Se, no início do século $\mathrm{xx}$, veículos como o rádio, a televisão e o cinema - comparados com o livro impresso -, foram capazes de acelerar sobremaneira os processos comunicativos, levando grande quantidade de signos de forma rápida e intensa a seus receptores (Daniels, 2002), o computador, através do desenvolvimento da World Wide Web, elevou o ritmo da comunicação ao patamar do imediato e do interativo, criando um espaço em que o mundo físico, de certo modo, chega a ser superado (Hayles, 1999). Em poucos termos, a grande rede fez emergir um novo universo, o mundo virtual ou, como tem sido chamado em alguns contextos, o ciberespaço (Lévy, 1999).

Além de admitir tanto a oralidade quanto a escrita, o ciberespaço cria um tipo específico de linguagem, na qual 
predominam a hipertextualidade e a hipermidialidade (Yoo, 2007). Em termos muito simplificados, o hipertexto pode ser compreendido como uma forma de escrita não-sequencial e multilinear. Alguns autores, como Marcuschi (2005), acreditam que o hipertexto, embora possua várias características particulares marcantes, deva continuar sendo considerado um texto, em sentido amplo, pois, segundo o autor, ainda se trata de um suporte de expressão predominantemente verbal, carregado de sentidos, que devem ser lidos ou interpretados por um receptor.

Por outro lado, contudo, o hipertexto não dá conta, isoladamente, de todos os processos semióticos que caracterizam a linguagem no ambiente virtual, principalmente a sua capacidade impressionante de agregar diferentes suportes semióticos, fenômeno frequentemente estudado, pelos pesquisadores da área, sob os conceitos da hipermidialidade, intermidialidade, multimidialidade, transmidialidade, entre outros (Yoo, 2007; Simanowski, 2002a; Simanowski, 2002b; Meyer; Simanowski; Zeller, 2006). Não obstante alguns meios mais antigos, como a televisão e o cinema, por exemplo, também realizarem diferentes tipos de integração entre a linguagem verbal e linguagens não-verbais, a multimidialidade propiciada pelo ambiente digital possui características próprias, principalmente a capacidade de hibridação dos vários meios (Wirth, 2006), o que leva alguns autores a preferirem 0 conceito transmidialidade para tratar do fenômeno.

O aspecto hipertextual dos discursos digitais leva o leitor a interagir fisicamente com o próprio texto, clicando sobre determinados links e comandos e, dessa forma, criando percursos diferenciados de leitura. Ademais, o leitor também pode interagir diretamente com o escritor, por exemplo, nos 
chats, realizando uma permuta constante de turnos comunicacionais: assim, o leitor torna-se uma espécie de escritor, e vice-versa (Araújo; Biasi-Rodrigues, 2007). De certo modo, a própria interatividade é responsável pelo surgimento da leitura não-sequencial e multilinear. Pelo fato de permitir diferentes percursos de leitura, o hipertexto apresenta-se como um desafio ao leitor, na medida em que o obriga a "fazer escolhas pertinentes para uma continuidade proveitosa e segura. E essas escolhas vão gerar caminhos diversos para cada leitor, de modo que as leituras, no caso do hipertexto, estão sujeitas a uma variabilidade muito maior do que no caso dos textos impressos" (Marcuschi, 2005, p. 25). Esse traço semiótico específico do hipertexto torna a leitura mais complexa, pois os diferentes percursos de leitura possíveis podem levar a resultados diferenciados, de acordo com as escolhas realizadas por parte do receptor em situações específicas (Manovich, 2003; Wandelli, 2003; Kirchof \& de Bem, 2006).

Os aspectos hipermidiais inerentes aos discursos digitais, por sua vez, tornam sua estrutura semiótica mais complexa, na medida em que não apenas apresentam simultaneamente, ao leitor, mais do que um sistema de signos, mas também criam sentidos específicos advindos das relações que se estabelecem entre as diversas mídias hibridadas. Num poema digital, por exemplo, a interação entre movimento e letra pode criar sentidos metafóricos surpreendentes, sendo que tais sentidos podem ser ampliados de modo ainda mais intenso caso o poema lance mão de recursos visuais e sonoros.

Discursos digitais e educação: ameaça ou benefício?

Já na década de 90, a discussão em torno do impacto da tecnologia digital sobre a linguagem e a cultura levou ao 
surgimento de duas posições extremas: de um lado, autores como Sven Birkerts (1991) afirmavam que a leitura em ambiente eletrônico representaria uma ameaça para os grandes benefícios alcançados pela humanidade a partir da cultura da escrita, levando a um empobrecimento linguístico, cognitivo e ético, devido àquilo que o autor denominou como "o princípio do imediato", que regeria as comunicações eletrônicas.

Esse ponto de vista se faz presente em várias discussões travadas no campo da Educação, ainda hoje, por exemplo, quando alguns educadores continuam perguntando se "a escrita na Internet pode ser compreendida como uma ameaça à língua" (Souza, 2007, p. 196). Em 2000, Alison Armstrong e Charles Casement lançaram um livro não apenas reproduzindo vários dos pontos de vista de Birkets, mas, inclusive, adicionando uma série de outras afirmações alarmistas: "Diferentemente da escrita, que encoraja a reflexão e uma consideração cuidadosa de vários pontos de vista, os programas de computador exigem ação imediata. [...] Velocidade e controle são enfatizados à custa da reflexão e do entendimento" (Armstrong \& Casement, $2001, p .23)$.

Além disso, certos estudos - como o de Manuel Castells, por exemplo -, nos alertam para o fato de que grande parte da cultura digital é "materializada por empresários movidos a dinheiro nas engrenagens da nova economia" (Castells, 2004, p. 53). A ligação da cultura digital com o mercado se faz perceber não apenas no contexto das novas possibilidades comerciais que enceta, mas também em sua ligação com o universo do entretenimento. Douglas Kellner (2002), entre outros autores, demonstrou que a Cultura da Mídia alia-se à Cultura do Consumo, criando um universo fictício dentro do qual o entretenimento é o valor mais destacado, na medida em que se revela altamente lucrativo. Nesse contexto, portanto, 
é inegável o fato de que grande parte dos produtos culturais gerados no âmbito da Internet e do computador está voltada para a cultura do consumo, preocupada com o lucro de grandes corporações e não, necessariamente, com questões educacionais, em sentido restrito.

Por outro lado, contudo, teóricos como o francês Pierre Levy (1999), entre outros, acreditam que, nos últimos anos, as novas tecnologias vêm criando uma nova forma de inteligência, uma inteligência coletiva, mais democrática e complexa do que a inteligência proporcionada pela cultura da escrita impressa. Segundo o autor, a principal consequência desse fato é uma profunda complexificação da cultura contemporânea, que passa a ser denominada, por Levy, de "cibercultura".

Autores como Jay David Bolter, George P. Landow e Robert Coover, entre vários outros, chegaram, inclusive, a afirmar que o hipertexto seria uma espécie de concretização dos ideais democráticos e libertários propagados por teóricos da pós-modernidade. Inspirado na afirmativa que Ted Nelson havia feito, ainda na década de 80, segundo a qual "o objetivo do computador é a liberdade humana", Landow (1994, p.1) afirma que, "assim como vários trabalhos recentes de pósestruturalistas como Barthes e Jacques Derrida, o hipertexto re-conceitua concepções convencionais e antigas sobre autores e leitores, bem como sobre os textos por eles lidos e escritos". Na esteira de Nelson, vários autores passaram a afirmar que "o que os pós-estruturalistas pensam teoricamente, os usuários de computadores realizam na prática" (Bellei, 2002, p. 52).

Nesse contexto de disputas acerca dos supostos benefícios e malefícios da tecnologia digital para a cultura, a linguagem e o ensino, talvez seja adequado situar a 
problemática em um prisma menos axiológico e mais fenomenológico. De um ponto de vista cultural, o surgimento de uma nova mídia sempre acarreta transformações de inúmeras ordens, que podem ser vistas como maneiras diferentes de representar e de fazer uso da linguagem. O intuito do presente artigo, portanto, é refletir sobre algumas das transformações mais evidentes no nível da leitura do texto literário, mais especificamente da poesia, na medida em que passa a ser produzida no ambiente eletrônico.

Entre certos críticos de literatura, há ainda resistência em reconhecer obras eletrônicas como pertencentes ao campo da arte ou da literatura. Nos Estados Unidos, por exemplo, até a década de 90, os artistas ligados às novas tecnologias, principalmente aos meios digitais, sofreram grande resistência por parte de instituições como museus e galerias, devido ao fato de que muitos críticos ainda não consideram as produções digitais como verdadeiras expressões artísticas (Manovich, 2003, p. 14).

Em parte, tal fenômeno pode ser explicado pelo fato de que, infelizmente, até o presente, a sociedade de consumo tem demonstrado muito mais interesse por essas novas formas de expressão do que o mundo propriamente acadêmico. Por outro lado, como demonstra Manovich, um dos principais problemas vinculado às artes e à literatura digital é que, no universo da crítica, ainda prevalecem concepções românticas, segundo as quais a verdadeira arte está indissociavelmente ligada a um único autor, a obra é sempre única e irreprodutível, há espaços (con)sagrados para a exposição dessas obras, como museus, galerias.

A literatura eletrônica abala os paradigmas românticos da linguagem e da tradição literária, pois, assim como as demais artes digitais, possui um número variável de estados, entre 
outros, devido à necessidade de interação entre o artistaautor e o usuário-leitor-fruidor. Ademais, seu caráter coletivo ou interativo, em alguns casos, questiona o próprio conceito da autoria: quantas pessoas participam efetivamente do processo de criação e da materialização de um poema em ambiente virtual? Por fim, tendo como principal meio de distribuição a rede, a arte digital também questiona a aura de lugares como museus, galerias e bibliotecas enquanto espaços privilegiados para a distribuição ou exposição da arte autêntica (Manovich, 2003, p. 13).

\section{A poesia digital}

Devido ao escopo reduzido do presente artigo, a seguir, serão analisados dois poemas produzidos por Carlos Vogt para - ambiente digital, no intuito de apresentar algumas de suas principais características semióticas, com ênfase no modo como a hipermidialidade e a intertextualidade são mobilizadas para produzir efeitos estéticos. Não se trata de uma reflexão com qualquer viés valorativo e tampouco conclusivo, mas de um ensaio que pretende lançar a lume alguns aspectos específicos da linguagem literária, na medida em que migra para o ambiente eletrônico.

Se a poesia impressa é pródiga em brincar com o espaço gráfico da página de papel, a poesia digital é pródiga em se apropriar de recursos característicos do espaço virtual, principalmente recursos possibilitados pela hipertextualidade e pela hipermidialidade. É o que se percebe logo no primeiro poema de Vogt que "aparece" na tela (o uso do verbo se justifica, uma vez que, nesse caso, o leitor não tem a necessidade de clicar sobre qualquer ícone). Ao digitar o endereço da página

http://www.joaobaptista.art.br/ilhas brasil - o leitor se 
depara com informações técnicas sobre a obra Ilhas Brasil e, logo a seguir, vislumbra o primeiro poema, "Ultrarrealismo": surge um desenho vermelho que poderia ser associado a um lápis para, logo depois, assumir a forma de uma barra que vai separando três sintagmas (A vida/ limita/ a arte), o que já aponta para 0 uso de recursos hipermidiais.

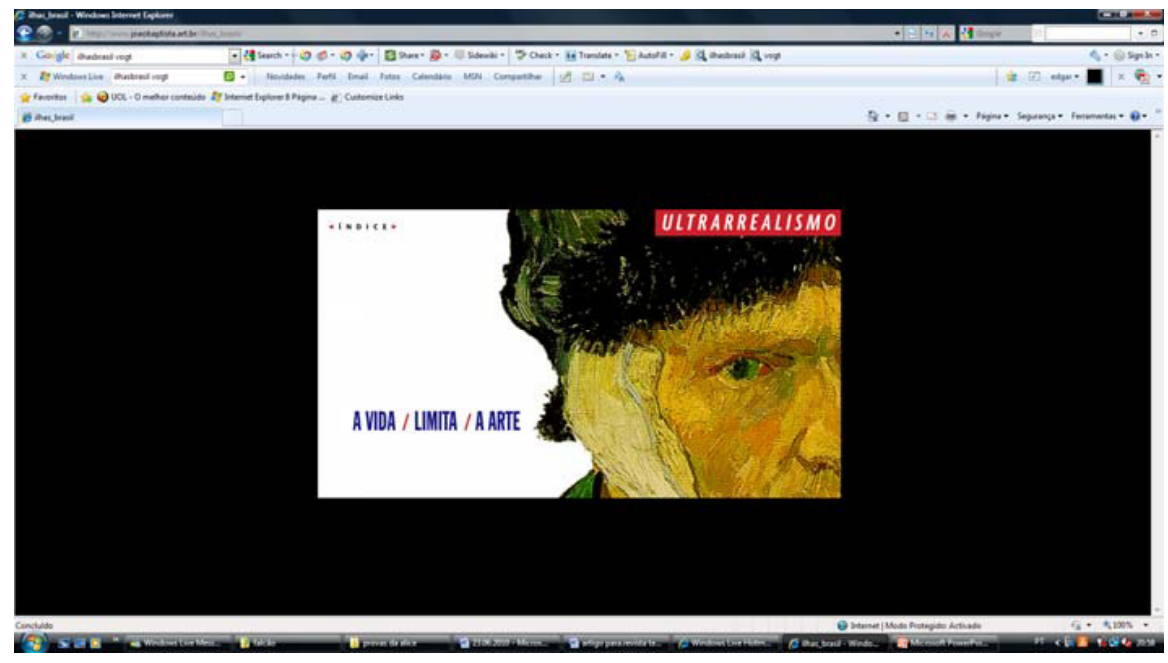

A barra (signo visual e, aqui, cinético) sugere o ato da escansão poética, o que caracteriza um caso típico de intermidialidade, na medida em que são integrados três sistemas semióticos: o sistema visual, o sistema cinético e o sistema literário. Visualmente, o sentido mais imediato da barra é de "seccionamento", aludindo à própria técnica poética da escansão. As barras servem como o limite das unidades de sentido, que são os versos. Cineticamente, o movimento realizado da parte superior em direção à parte inferior da tela confere um sentido de dinamicidade ao poema: por causa do movimento, o leitor tem um certo tempo para refletir sobre cada verso, isoladamente, e depois sobre o conjunto. Além disso, o vermelho reitera a sugestão de algo proibido e que não deve ser ultrapassado.

No que tange ao sistema propriamente literário, chama atenção, de imediato, o uso paródico dos versos, que invertem 
deliberadamente o conhecido aforismo: "A vida imita a arte", que, por sua vez, já é uma inversão quanto à concepção antiga da arte como mimese da natureza. Segundo o poema de Vogt, portanto, à vida cabe o papel de censora e de limitadora da atuação da arte, o que abre caminhos diversos para discussão. A imagem que aparece à direita da tela é de Van Gogh, sem sua orelha direita. A clara associação do poema com a vida de Van Gogh, que teria cortado sua orelha - uma iteração semântica da ideia da escansão, apresentada visualmente pela barra - torna o poema ainda mais polissêmico: o corte poderia ser entendido aqui como uma metáfora da limitação da vida (ou da arte?), o corpo limitado pela ausência, a mutilação como o limite máximo (o ultra) do real (Ultrarrealismo), entre outras tantas possibilidades.

"Ilhas Brasil" é composto de dezesseis poemas, tendo cada um deles suas peculiaridades e diferentes usos de recursos digitais: ora os poemas conjugam som e imagem (estática ou em movimento), ora imagem, texto verbal e som. O poema "Amarelinha", por sua vez, destaca-se pelo uso de potencialidades hipertextuais, na medida em que permite, ao leitor, intervir diretamente na própria construção do poema.

Num primeiro momento, existe uma referência explícita ao conhecido jogo da amarelinha. Por outro lado, levando em conta o sistema literário, principalmente obras de importância no cenário da literatura experimental, pode-se pensar em uma referência intertextual à obra Jogo da Amarelinha, de Cortazar, cuja concepção estética fundamental está baseada justamente nessa ideia de um jogo que permite, ao leitor, construir seus próprios percursos de leitura. De modo muito semelhante à obra de Cortazar - que também indica ao leitor maneiras diferenciadas de realizar a leitura - 
também "Amarelinha" de Vogt traz a seguinte orientação: "Faça o seu poema. Clique e arraste as palavras".

Expostas sobre fundo alaranjado e com as letras em laranja mais escuro, já rompendo com a expectativa do amarelo, apresenta-se $O$ poema "O FILME/AFIRMA E NEGA/O ROMANCE/LIBERTA O TRABALHO/OPRIME/A VINGANÇA/CEGA/O AMOR/REDIME" .

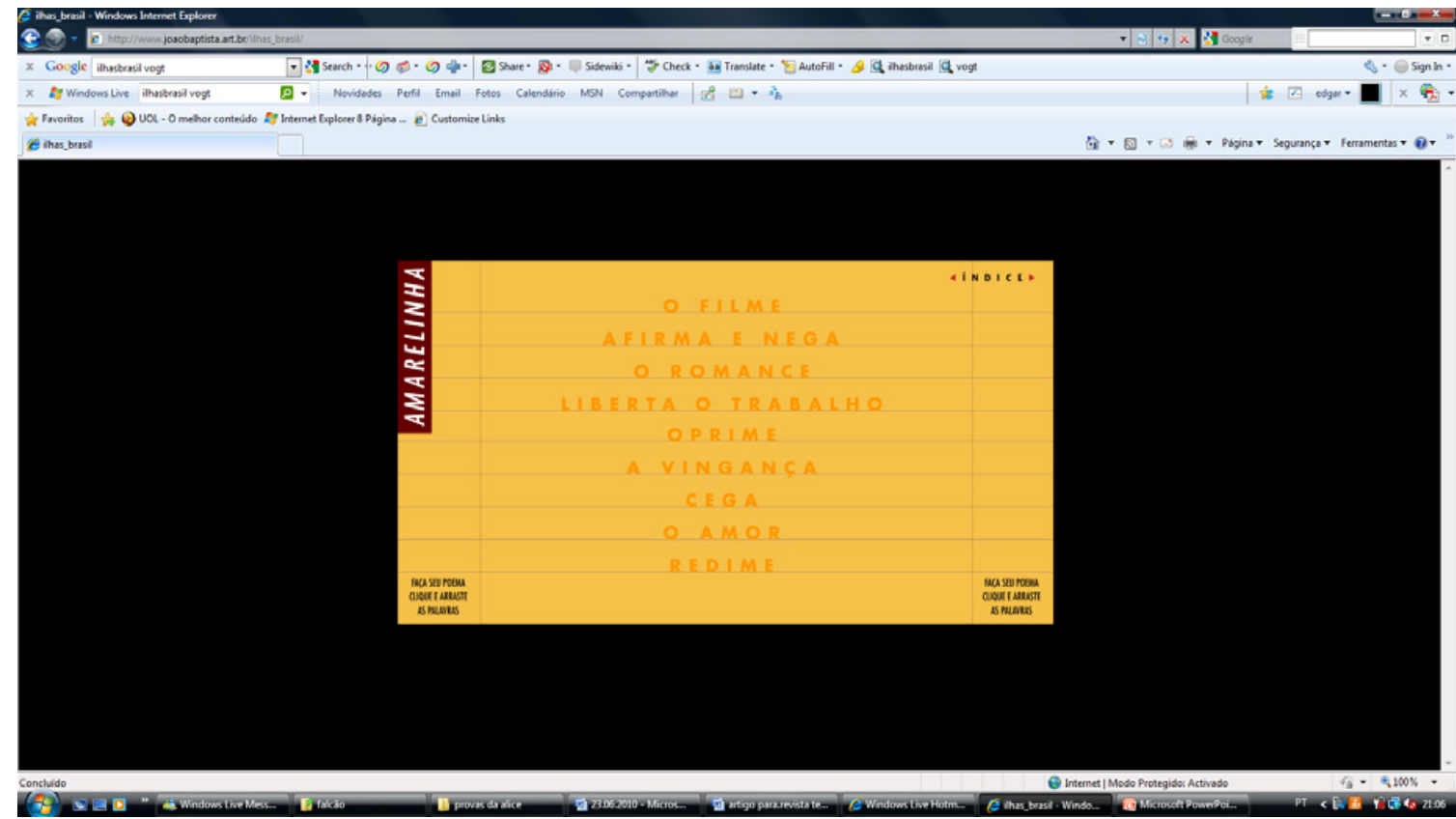

O fundo da tela consiste na representação de uma folha (pautada) de caderno, sugerindo a ideia de rabisco, de algo inacabado, o que contribui para o principal eixo semântico do poema, uma vez que o leitor é convidado a dar continuidade ao trabalho da composição. A partir de conceitos/questões como o amor, o romance, o filme, entre outros, o leitor pode reordenar o poema a seu bel-prazer, chegando, cada vez, a um novo poema, do qual pode ser considerado um co-autor. Os resultados são menos importantes do que a possibilidade de estabelecer um pacto com o autor, com a máquina ou consigo mesmo, a partir do jogo poético. 
Por outro lado, é necessário ressaltar que a liberdade da leitura de um texto hipertextual é sempre limitada e, de certa forma, pré-estabelecida. Apesar de o leitor colaborar na construção de diferentes leituras - cada uma delas levando a um novo poema -, esses caminhos não são infinitos e seus percursos são pré-construídos pelo poeta e/ou pelo programador. Além da seleção dos próprios versos que dão início ao percurso de leitura, há também vários outros limitadores. Por exemplo, como o poema Amarelinha não apresenta qualquer verbo no plural (oprime, liberta, afirma), - leitor, em princípio, é motivado a escolher, separadamente, as palavras "o amor" e "a vingança", sob pena de romper também com a ideia de concordância. Por outro lado, nada impede que sobreponha todas as palavras e versos, de maneira que surjam sentidos ilógicos ou alógicos: se a ideia é de ruptura e de jogo, por que não? Assim, se há possibilidade de interatividade na proposta dos poemas hipertextuais, ela é sempre limitada pelo sistema que a gerou bem como por uma concepção prévia do poeta.

Considerações finais

No presente artigo, procurou-se argumentar em favor da necessidade de se pensar a relação dos novos gêneros eletrônicos com a leitura e a educação a partir do âmbito da própria cibercultura, focalizado-se a poesia digital como um dentre tantos outros gêneros eletrônicos capazes de revelar algumas das transformações estéticas e semióticas pelas quais passa a linguagem na medida em que se configura no meio eletrônico.

o texto literário é um recurso de ensino amplamente utilizado na escola, não se restringindo apenas às aulas específicas de literatura: textos poéticos e ficcionais são 
empregados, desde as séries iniciais, como recurso pedagógico para alfabetização e letramento, até as séries mais avançadas, como veículos de motivação para inúmeras discussões interdisciplinares. Levando-se em conta que a literatura é uma forma artística de representação da cultura, a literatura eletrônica se apresenta como um objeto privilegiado para desencadear um estudo a respeito da relação entre as novas tecnologias, a cultura e o Ensino.

Por se tratar de um signo literário muito recente, a poesia digital encontra-se ainda em fase de experimentação, e sua recepção tem ocorrido de modo limitado, ainda pouco ligada aos ambientes formais de Ensino, como a Universidade e a Escola: poucos são os professores que incluem a poesia digital como objeto de estudo e de fruição em suas aulas. Por outro lado, no entanto, visto estar disponível na rede, muitas vezes, em sites criados por poetas já consagrados pela produção de poemas impressos, pode-se dizer que, informalmente, a poesia digital possui um alto potencial de circulação e recepção.

Nesse sentido, pode-se concluir que a reflexão sobre as estratégias de representação mobilizadas pelos novos gêneros digitais - a exemplo da poesia digital - pode constituir um precioso auxílio para a superação de discussões polarizadas em torno de supostos benefícios e malefícios causados por textos eletrônicos e digitais. Antes de auxiliar ou de prejudicar o ensino e a própria educação, em sentido amplo, os gêneros eletrônicos são artefatos culturais e, enquanto tais, produzidos por uma cultura não mais centralizada sobre a escrita em forma impressa.

Aproximar a poesia digital ao Ensino é uma estratégia produtiva não apenas para a construção de aulas mais interativas, mas também para a própria vivência e reflexão 
crítica acerca da cibercultura e da cultura eletrônica. Por fim, cabe retomar a intenção do presente artigo: apresentar e defender o argumento segundo o qual é a partir da integração de objetos culturais efetivamente produzidos no âmbito da cultura digital que o ensino poderá se abrir para a discussão sobre as novas tecnologias e, talvez, inclusive para a produção de novas práticas pedagógicas, em que essas tecnologias não servirão apenas como uma mera ferramenta ou como uma forma de se diferenciar no mercado de trabalho (Arruda, 2004, p. 51), mas sim, talvez, também como um meio para a ampliação de nossos horizontes cognitivos.

A tecnologia, enquanto instrumental, depende da adesão do educador para desenvolver seu potencial de ampliação do conhecimento. Nesse sentido, uma prática educacional simultaneamente crítica e consciente do papel do professor frente às novas tecnologias que se apresentam deve levar em conta a especificidade da linguagem em ambiente virtual, a fim de se evitar idealismos ingênuos, de um lado, e alarmismos anacrônicos, de outro.

Referências

ARAÚJo, Júlio César (Org.) Internet \& Ensino: Novos gêneros, outros desafios. Rio de Janeiro: Lucerna, 2007.

ARAÚJo, Júlio César; CostA, Nonato. Momentos interativos de um Chat Aberto. A composição do gênero. In: ARAÚJo, Júlio César (Org.) Internet \& ensino: novos gêneros, outros desafios. Rio de Janeiro: Lucerna, 2007. p. 21-34. ARAÚJO, Júlio César; BIASI-RODRIGUES, Bernardete. Questões de estilo no gênero chat aberto e implicações para o ensino de língua materna. In: ARAÚJO, Júlio César (Org.) Internet \& 
ensino: novos gêneros, outros desafios. Rio de Janeiro: Lucerna, 2007. p. 78-92.

ARMSTRONG, Alison; CASEMENT, Charles. A criança e a máquina: como os computadores colocam a educação de nossos filhos em risco. Porto Alegre: Artmed, 2001.

ARRUDA, Eucidio. Ciberprofessor: novas tecnologias, ensino e trabalho docente. Belo Horizonte: Autêntica/FCH-FUMEC, 2004. BELLEI, Sergio Luiz Prado. O livro, a literatura e o computador. São Paulo: Educ/ Florianópolis: UFSC, 2002. BIRKERTS, Sven. The Gutenberg elegies - the fate of reading in an electronic age. New York: Ballentine Books, 1991.

CASTELLS, Manuel. A galáxia da Internet: reflexões sobre a Internet, os negócios e a sociedade. Rio de Janeiro: Zahar, 2003.

CoscARelli, Carla Viana; RIBEIRo, Ana Elisa. Letramento digital: aspectos sociais e possibilidades pedagógicas. Belo Horizonte: Ceale; Autêntica, 2005.

DANIELS, Dieter. Kunst als Sendung: von der Telegrafie zum Internet. München: Beck, 2002.

ECO, Umberto. A misteriosa chama da rainha Loana: um romance ilustrado. Rio de Janeiro/ São Paulo: Record, 2005.

HAYLES, N. Katherine. How we became posthuman: virtual bodies in cybernetics, literature, and informatics. Chicago: The University of Chicago Press, 1999.

HOFFMEYER, Jesper. Signs of meaning in the universe. Bloomington \& Indianapolis: Indiana University Press, 1996. KELLNER, Douglas. A cultura da mídia - estudos culturais: identidade e política entre o moderno e o pós-moderno. Bauru, SP: EDUSC, 2001. 
KIRCHOF, Edgar Roberto; DE BEM, Isabella Vieira. O impacto da tecnologia sobre a literatura contemporânea. Revista Texto Digital, Florianópolis, ano 2, n.3, 2006.

KIRCHOF, Edgar Roberto. A poesia digital sob a perspectiva da Semiótica Evolutiva da Cultura. In: CORRÊA, Alamir Aquino (Org.). Ciberespaço: mistificação e paranóia. Londrina: Universidade Estadual de Londrina, 2008. p. 128-137.

KOCH, Walter A. evolution of culture. Bochum: Brockmeyer, 1989 .

LANDOW, George P. Hypertext theory. Baltimore: Johns Hopkins Univ. Press, 1994.

LEVY, Pierre. Cibercultura. Lisboa: Ed. 34, 1999.

MANOVICH, Lev. New Media from Borges to HTML. In: WARDRIPFRUIN, Noah; MONFORT, Nick. The new media reader. Cambridge \& Massachusetts: London, 2003.p. 13-25.

MARCUSCHI, Luiz Antônio. A coerência no hipertexto. In: COSCARELli, Carla Viana; RIBEIRO, Ana Elisa. Letramento digital: aspectos sociais e possibilidades pedagógicas. Belo Horizonte: Ceale; Autêntica, 2005. p. 185-207.

MARCUSCHI, L. A.; XAVIER, A. C. (Orgs.). Hipertexto e gêneros digitais: novas formas de construção de sentido. Rio de Janeiro: Lucerna, 2004.

MEYER, Urs; SIMANOWSKI, Roberto; ZELLER, Christoph. Transmedialität: zur Ästhetik paraliterarischer Verfahren.Göttingen: Wallstein Verlag, 2006. SIMANOWSKI, Roberto. Interfictions: vom Schreiben im Netz. Frankfurt am Main: Suhrkamp, 2002a.

- Geburt und Entwicklung der digitalen Literatur. In: - (Ed.) Literatur.digital: Formen und Wege einer neuen Literatur. München: Deutscher Taschenbuch Verlag, 2002b, p. 56-92. 
SoUZA, Socorro Claudia Tavares de. As formas de interação na Internet e suas implicações para o ensino de Língua Materna. In: ARAÚJO, Júlio César (Org.). Internet \& ensino: novos gêneros, outros desafios. Rio de Janeiro: Lucerna, 2007 . p. 196-204.

WANDELLI, Raquel. Leituras do hipertexto: viagem ao Dicionário Kazar. Florianópolis/São Paulo: UFSC / Imprensa Oficial, 2003.

WIRTH, Uwe. Hypertextuelle Aufpropfung. In: MEYER,Urs; SIMANOWSKI, Roberto; ZELLER, Christoph. Transmedialität: zur Ästhetik paraliterarischer Verfahren. Göttingen: Wallstein Verlag, 2006 .

Yoo, Hyun-Joo. Text, Hypertext, Hypermedia: Ästhetische Möglichkeiten der digitalen Literatur mittels Intertextualität, Interaktivität und Intermedialität. Würzburg: Königshausen \& Neumann, 2007. 